\title{
Combination of capecitabine and ludartin inhibits colon cancer growth in mice
}

\author{
Li-xia Huang ${ }^{1}$, Min-yu Zhong ${ }^{2}$, Dan Dan ${ }^{2}$, Xiao-mei Yang ${ }^{2}$, Hui Qiu ${ }^{2}$ and Pei- \\ zhong Guo ${ }^{2 *}$ \\ ${ }^{1}$ School of Medicine, Jianghan University, WuHan, HuBei Province 430056 2Department of Oncology, Wuhan Integrated \\ Integrated TCM \& Western Medicine Hospital, Wuhan HuBei 430022, ${ }^{2}$ School of Medicine, Jianghan University, WuHan, \\ HuBei Province 430056, China
}

*For correspondence: Email: hlxgw2011@163.com; Tel/Fax: +862785379530

Sent for review: 17 April 2017

Revised accepted: 6 October 2017

\begin{abstract}
Purpose: To investigate the efficacy of capecitabine and ludartin in the treatment of colon cancer in mice.

Methods: Mice model of colon cancer was used in this study. Quantitative real-time polymerase chain reaction (Qrt-PCR) was used to quantify the expression of vascular endothelial growth factor (VEGF) mRNA. Micro-vessel density was assessed using immunohistochemical analysis.

Results: When administered separately, capecitabine and ludartin treatments significantly suppressed tumor growth in the mice model of colon cancer for 4 weeks, compared to control group. Coadministration of capecitabine and ludartin significantly inhibited tumor growth for 6 weeks $(p<0.05)$. Symptoms of colon cancer such as weight loss, skin discoloration and leukopenia were observed in untreated control group. However, these symptoms were completely absent in the group treated with combination of capecitabine and ludartin. The combined treatment also prevented colon cancer-induced increase in white blood cell (WBC) count, and increased median survival time of colon cancer mice from 38 to 55 days. Expression of VEGF in combination (capecitabine + ludartin) treatment group was significantly lower than in the control, i.e., untreated group $(p<0.05)$. The combination treatment group also had significantly lower micro-vessel density in the tumor tissues, compared to the untreated control mice $(p<0.05)$.

Conclusion: These results show that a combination treatment of capecitabine and ludartin effectively inhibits colon tumor growth and angiogenesis in mice via a mechanism involving suppression of VEGF expression. Thus, capecitabine and ludartin combination is a potentially suitable treatment for colon cancer.
\end{abstract}

Keywords: Colon cancer, Mice, Ludartin, Leukopenia, VEGF expression, Angiogenesis

Tropical Journal of Pharmaceutical Research is indexed by Science Citation Index (SciSearch), Scopus, International Pharmaceutical Abstract, Chemical Abstracts, Embase, Index Copernicus, EBSCO, African Index Medicus, JournalSeek, Journal Citation Reports/Science Edition, Directory of Open Access Journals (DOAJ), African Journal Online, Bioline International, Open-J-Gate and Pharmacy Abstracts

\section{INTRODUCTION}

Colon cancer, one of the common malignant tumors of the digestive tract, occurs at the junction between the rectum and the sigmoid colon $[1,2]$. It is more common in males than in females and affects mostly people in the age group of 50-60 year [1,2]. Studies have revealed that colon cancer progression involves several mechanisms such as alteration of the apoptotic pathway and mutation of cell cycle components [ $\underline{3}-\underline{6}]$. It has also been observed that activation of infiltrating immune cells and immunosuppressive pathways play vital role in the development and progression of colon cancer [7]. Treatment strategies for colon cancer include 
chemotherapy, radiotherapy and surgical intervention [?].

Ludartin is a sesquiterpene lactone with cytotoxic, antitumor and anti-bactericidal properties [8]. Synthetic analogs of ludartin have also shown promising pharmaceutical activities [9]. In view of the antitumor properties of ludartin, the present study was designed to investigate its effect on colon tumor growth in s mice model. Selective delivery of 5-fluorouracil into tumor cells is achieved by the use of capecitabine [10]. Capecitabine, used alone or in combination with other drugs has been investigated for the treatment of gastric cancers [10]. High doses of capecitabine cause result in some unwanted side effects such as drug resistance, diarrhoea and lymphopenia, but at lower doses, the drug is effective for cancer treatment [10].

The present study investigates the effect of combined treatment with ludartinin and capecitabine on colon tumor growth in a mice model of colon cancer.

\section{EXPERIMENTAL}

\section{Animals}

Twenty five female nude BALB/c mice, aged 7 8 weeks, were supplied by the Animal Experiment Centre of Beijing, China. The mice were housed under conditions free from pathogens at room temperature, $55 \%$ humidity and circadian $12 \mathrm{~h}$ light/12 h dark rhythm. All the animals were allowed free access to CLEA rodent diet (CA-1) and tap water.

\section{Chemicals and cell culture}

Ludartin amd azoxymethane (AOM) were purchased from Sigma-Aldrich (St. Louis, MO, USA). Capecitabine was supplied by Roche Pharmaceutical Company (Nutley, NJ, USA). Dextran sulfate sodium (DSS; cat. no. 160110) was product of MP Biomedicals, LLC (Aurora, $\mathrm{OH}$ ). HCT-116 cancer cell line was obtained from Cell Resource Centre for Biomedical Research, Aging and Cancer, Tohoku University, Japan. The cells were cultured in RPMI- 1640 medium at $37{ }^{\circ} \mathrm{C}$ under an atmosphere of $5 \% \mathrm{CO}_{2}$ and 95 $\%$ air. The medium was supplemented with $10 \%$ NBS containing penicillin $(100 \mathrm{U} / \mathrm{mL})$ and streptomycin $(100 \mu \mathrm{g} / \mathrm{mL})$.

\section{Animal experiment design}

The experimental procedures used in the animal studies were performed in accordance with the international Guide for the Care and Use of
Laboratory Animals [11]. Approval for the study was obtained from the Ethics Committee of Hebei United University for the use of animals. Colon cancer was induced in mice by administration of AOM and DSS. The mice were divided into five groups of 5 animals each. Four groups received AOM and DSS intraperitoneally and the normal control was given saline only. The AOM was given through intraperitoneal injection at a dose of $10 \mathrm{mg} / \mathrm{kg}$ body weight. An aqueous solution of DSS [ $(1.5 \mathrm{~g}$ of DSS was dissolved in $100 \mathrm{~mL}$ of water to get $1.5 \%(\mathrm{w} / \mathrm{v})$ ] was given to the mice orally one week after AOM injection. Mice in the capecitabine, ludartin and combination treatment groups were administered $200 \mathrm{mg} / \mathrm{kg}$ capecitabine, $10 \mu \mathrm{M}$ ludartin, and 100 $\mathrm{mg} / \mathrm{kg}$ capeitabine plus $10 \mu \mathrm{M}$ ludartin, respectively daily by gavage for one month. At the end of the treatments, the mice were sacrificed under $10 \%$ chloral hydrate $(3 \mathrm{mg} / \mathrm{kg})$ anaesthesia administered intraperitoneally.

\section{Analysis of tumor growth and side effects}

During the study, mice in all groups were weighed and examined carefully to record changes in body weight and physical appearance. Blood samples were collected for determination of white blood cell (WBC) count.

\section{Real-time polymerase chain reaction (RT- PCR) analysis}

After the mice were sacrificed, the colon tumour was excised and stored under liquid nitrogen till further analysis. Total RNA was extracted from the colon tumor tissue using TRIzol reagent (Invitrogen, USA). Reverse transcription of the extracted RNA was performed using oligo (dT) primers. Analysis of the mRNA expression was carried out by quantitative real time reverse transcription-PCR. The primers used for reverse transcription of VEGF were 5'-GAGCCTTGCC TTGCTGCTCTAC for forward and 5'CACCAGGGTCTCGATTGGATG for backward. For $\beta$-actin, the primers were 5'-TGGCACC CAGCACAATGAA (forward) and 5'-CTAAGT CATAGTCCGCCTAGAAGCA (backward). Amplification of the cDNAs was done over 45 cycles using PCR Thermal Cycler (Takara Bio) and SYBR Green. The amplification involved a two-step procedure consisting of $5 \mathrm{sec}$ at $95{ }^{\circ} \mathrm{C}$ and $30 \mathrm{sec}$ at $60^{\circ} \mathrm{C}$.

\section{Analysis of VEGF and CD31 in colon cancer tissues}

Colon tumor tissues were fixed in $10 \%$ buffered formalin phosphate. The fixed tissues were embedded in paraffin and subsequently sliced 
into thin sections for immunohistochemical examination using PV-9000 kit (Beijing Zhongshan Goldenbridge Biotechnology Company, Beijing, China). The tissue sections were de-waxed in boiling xylene and then treated with VEGF rabbit anti-human monoclonal antibody (Fuzhou Maixin Company, China), and CD31 rat anti-mouse monoclonal antibody (Dako, Japan) at $1: 100$ dilution. The treatment was performed for 3 minutes under pressure in citrate buffer ( $\mathrm{pH}$ 6.0). Expression of VEGF was indicated by presence of stained cytoplasm VEGF [12].

\section{Determination of micro-vessel density}

Micro-vessel density was determined immunohistochemically [13], using antibodies against endothelial marker CD31. Initially, the sections were examined at a magnification of $x$ 40 and $x$ 100, to localize regions of high neovascularization. Endothelial cells that stained yellow-brown were taken as micro-vessel. The selected microvessels were further examined at a high magnification (x 200) to determine the micro-vessel density (MVD) count, and the images were captured with Zeiss fluorescence microscope (Zeiss Inc.) equipped with an Olympus N547 digital camera (Olympus).

\section{Statistical analysis}

Results are presented as mean \pm S.E.M. Analysis of data on survival was performed using Kaplan Meier analysis. ANOVA and StudentNewman-Keuls tests were also used for data analysis. SPSS 17.0 software package was used for all statistical analyses. Values of $p<0.05$ were considered statistically significant.

\section{RESULTS}

\section{Effect of capecitabine and ludartin on tumour growth}

In the control group, tumour growth was prompt and after 6 weeks, all mice had large tumour sizes (Figure 1). Tumour growth was delayed markedly in the capecitabine-treated group of mice for 4 weeks $(p<0.02$; Figure 1). Treatment with ludartin exhibited tumor growth-delaying effect similar to that of capecitabine. Combination of capecitabine and ludartin brought about significant inhibition of tumour growth, so much so that there was no tumour growth was observed 6 weeks after treatment $(p<0.05$; Figure 1).

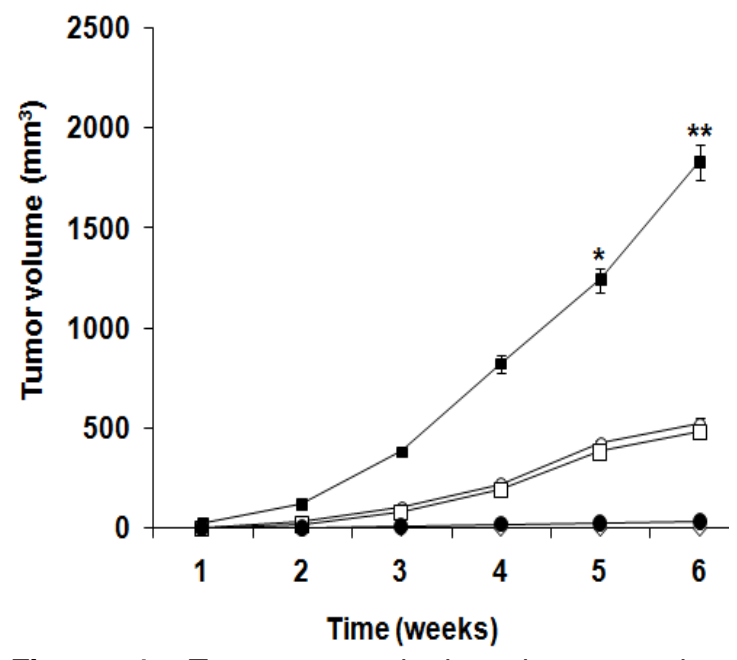

Figure 1: Tumour growth in mice treated with capecitabine, ludartin, and combination of capecitabine and ludartin. ${ }^{*} p<0.05$ and ${ }^{\star *} p<0.02$ of control verses normal ( $\diamond$ Normal, - Untreated, $\circ$ Ludartin $\square$ Capecitabine, $\bullet$ Combination treatment)

\section{Effect of capecitabine and ludartin on WBC count}

Mice in the control, untreated group showed various symptoms such as weight reduction, skin discoloration and leukopenia during the 6-week study. However, no such symptoms were observed in the mice treated with capecitabine, ludartin or combination of capecitabine and ludartin. After two weeks of tumour establishment, WBC count was same in all the groups of mice. No significant changes in WBC count were seen in the capecitabine, ludartin or combination (capecitabine and ludartin) treatment groups. On the other hand, there were significant decreases in WBC count in the control group within two weeks $(p<0.05$; Figure 2).

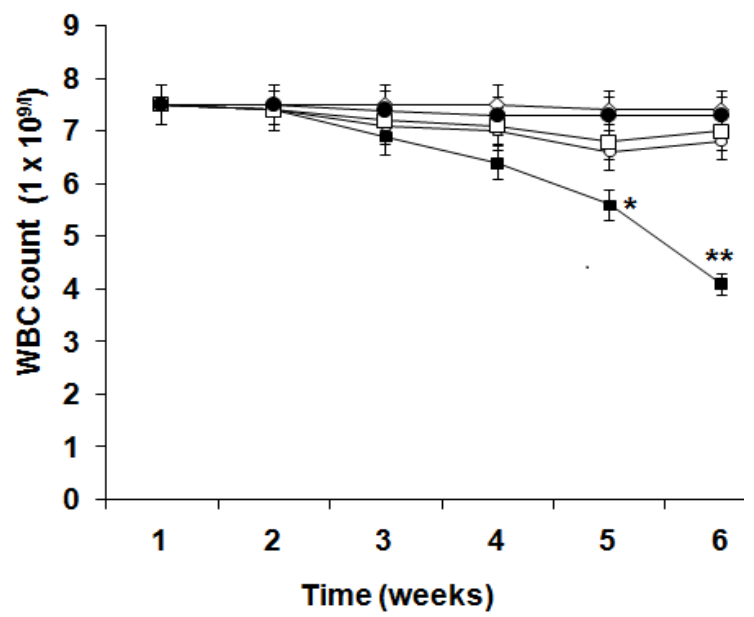

Figure 2: Effect of AOM/DSS and treatment on WBC count of mice. ${ }^{*} p<0.05$ and ${ }^{* *} p<0.05$ of untreated control verses normal. ( $\diamond$ Normal, - Untreated, $\odot$ Ludartin $\square$ Capecitabine, $\bullet$ Combination treatment) 
Effect of capecitabine and ludartin on mice survival

Mice in the control group had median survival time of 38 days. The median survival times of mice in capecitabine and ludartin treatment groups were 49 and 50 days, respectively $(p<$ 0.02 ). The median survival time of mice in the combination treatment group was 55 days $(p<$ 0.02).

\section{Effect of capecitabine and ludartin on VEGF expression}

The expression of VEGF gene was significantly higher in the untreated control mice group, when compared to normal healthy mice (Figure 3). However, VEGF expression was significantly lower in the capecitabine and ludartin treatment groups, relative to the control group. Expression of VEGF in the combination (capecitabine and ludartin) treatment group was significantly lower when compared to the capecitabine and ludartin treatment groups $(p>0.05$; Figure 3$)$.

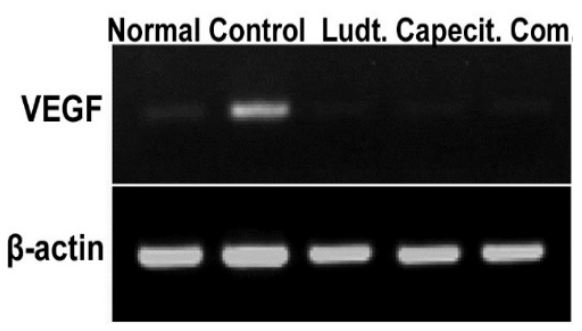

Figure 3: Effect of capecitabine, ludartin and combination of capecitabine plus ludartin on VEGF expression in the colon of mice with colon tumour

\section{Effect of capecitabine and ludartin on colon tissue histopathology of mice}

Histopathological examination of tissues from the mice of control group showed markedly higher count of microvessels, when compared to the normal mice (Figure 4). Microvessel count was lower in the capecitabine and ludartin treatment groups of mice, relative to the control group. Combination treatment produced even lower micro-vessel counts in the colon tumour tissues, when compared to the capecitabine or ludartin treated mice (Figure 4).

\section{DISCUSSION}

Investigation of the effect of capecitabine and ludartin on colon tumour growth either alone or in combination revealed that combination of capecitabine and ludartin was an effective treatment regimen. The combination of capecitabine and ludartin inhibited colon tumor growth and angiogenesis. Therapeutic strategies using known drugs in combination with phytochemicals have been found effective for treatment of various disorders, and are highly encouraged [14,15]. In the present study, the effect of capecitabine and ludartin separately or in combination on colon tumor angiogenesis in a mice model was investigated. The results showed that tumor growth in control mice was prompt, resulting in large tumour size in all the animals within one month.

However, capecitabine treatment caused marked delay in tumour growth for 21 days. Ludartin treatment also exhibited tumour growth-inhibiting. However the most effective inhibition of tumour growth was produced by the combination of two drugs, which resulted in absence of tumor growth for one month. At lower doses, capecitabine is efficient for cancer treatment because of its specificity for tumour cells [10]. Mice in the control group showed various symptoms such

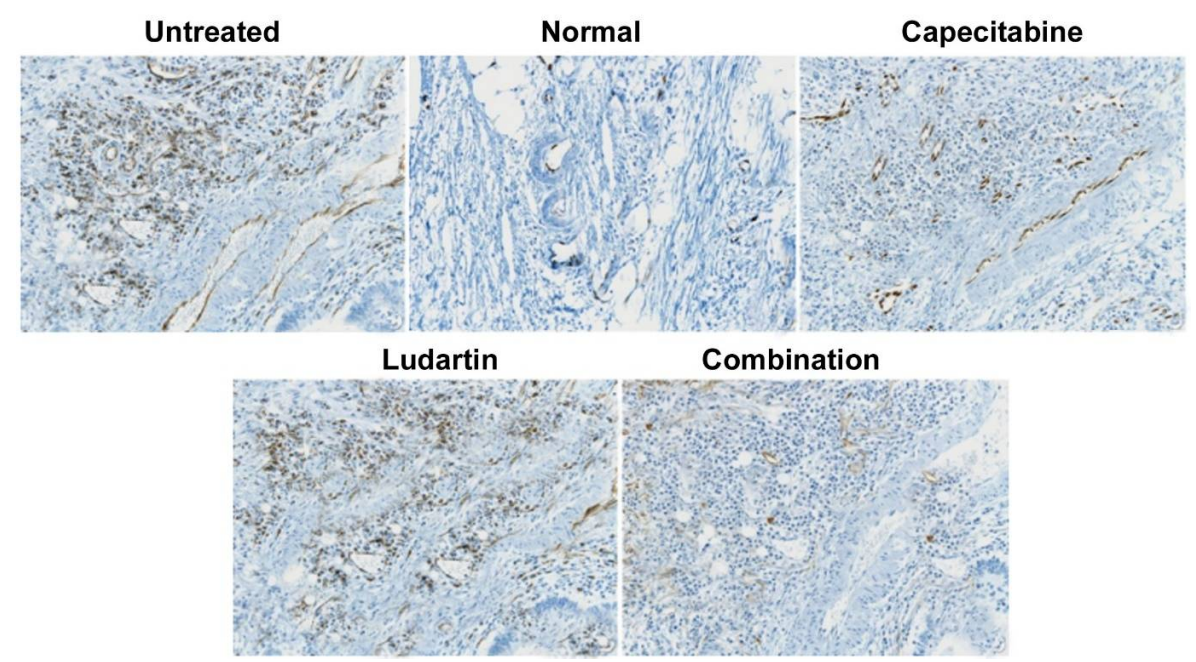

Figure 4: Effect of capecitabine, ludartin and the combination treatment on AOM/DSS-mediated increase in colon micro-vessel density in colon cancer model mice. (x 200) 
as weight reduction, skin discoloration and leukopenia, all of which were reversed by capecitabine, ludartin or combination (capecitabine and ludartin) treatment.

VEGF plays an important role in the progression of tumour angiogenesis; its expression is a characteristic of angiogenesis [16,17]. Studies have shown that higher expression of VEGF in tumor cells is associated with the development of drug resistance [18-20]. The present study showed that in the colon tumor cells of control, untreated group, the expression of VEGF gene was markedly higher than that in normal, healthy control mice. However, the expression of VEGF in the colon tumor-bearing mice was markedly reduced on treatment with combination of capecitabine and ludartin. Higher micro-vessel density in tumour cells is considered to be the characteristic feature of angiogenesis [21]. The expression of VEGF and micro-vessel count are directly related [22]. In the present study, results from histopathological examination of tumour tissues of the untreated, control mice showed markedly higher count of micro-vessels than corresponding values for healthy control mice. Treatment with combination of capecitabine and ludartin led to a significant decrease in the count of micro-vessels in the tumour tissues, relative to the capecitabine or ludartin treatment when used alone.

\section{CONCLUSION}

The findings of this study show that the combination of capecitabine and ludartin inhibits colon tumour growth and angiogenesis in mice via suppression of VEGF expression. Thus, capecitabine and ludartin combination has a potential for development into a suitable medication for the treatment of colon cancer.

\section{DECLARATIONS}

\section{Acknowledgement}

This study was supported by Medical Science Research Project of Wuhan Health and Family Planning Commission (no. WZ17C02).

\section{Conflict of Interest}

No conflict of interest associated with this work.

\section{Contribution of Authors}

The authors declare that this work was done by the authors named in this article and all liabilities pertaining to claims relating to the content of this article will be borne by them.

\section{Open Access}

This is an Open Access article that uses a funding model which does not charge readers or their institutions for access and distributed under the terms of the Creative Commons Attribution License (http://creativecommons.org/licenses/by/ 4.0) and the Budapest Open Access Initiative (http://www.budapestopenaccessinitiative.org/rea d), which permit unrestricted use, distribution, and reproduction in any medium, provided the original work is properly credited.

\section{REFERENCES}

1. Yang TM. Clinical pathological features and survival rate of 116 cases of colorectal cancer. Chin $J$ Med Guide2014; 16: 602-603.

2. Zhao $S$, Xue B. Clinical and pathological features of rectal cancer in young patients. Mod Oncol 2013; 21: 1296-1298.

3. Tominaga O, Nita ME, Nagawa H, Fujii S, Tsuruo T, Muto T. Expressions of cell cycle regulators in human colorectal cancer cell lines. Jpn J Cancer Res 1997; 88: 855-860.

4. Rupnarain C, Dlamini Z, Naicker S, Bhoola K. Colon cancer: Genomics and apoptotic events. Biol Chem 2004; 385: 449-464.

5. Karin M. NF-kappaB and cancer: Mechanisms and targets. Mol Carcinog 2006; 45: 355-361.

6. Whisenant J, Bergsland E. Anti-angiogenic strategies in gastrointestinal malignancies. Curr Treat Options Oncol 2005; 6: 411-421.

7. Pancione M, Giordano G, Remo A, Febbraro A, Sabatino $L$, Manfrin E, Ceccarelli $M$, Colantuoni V. Immune escape mechanisms in colorectal cancer pathogenesis and liver metastasis. J Immunol Res 2014: 2014: 686879.

8. Rabe J, Hoffmann HMR. Synthesis and biological activity of a-methylene-Y-butyrolactones. Angew Chem Int Ed Eng 1985; 24: 94.

9. Rodriguez E, Towers GHN, Mitchell JC. Phytochem 1976; 15: 1573.

10. Tham CK, Choo SP, Poon DY. Capecitabine with radiation is an effective adjuvant therapy in gastric cancers. World J Gastroenterol 2010; 16: 3709-3715.

11. European Commission. Directive 2010/63/EU on the protection of animals used for scientific purposes [cited 2015 June 11]. Available from: http://ec.europa. eu/environment/chemicals/lab_animals/legislation_en.ht $m$

12. Bocci G, Falcone A, Fioravanti A, Orlandi P, Di Paolo A, Fanelli G, Viacava P, Naccarato AG, Kerbel RS, Danesi $R$, et al. Antiangiogenic and anticolorectal cancer effects of metronomic irinotecan chemotherapy alone and in

Trop J Pharm Res, November 2017; 16(11): 2627 
combination with semaxinib. $\mathrm{Br} J$ Cancer 2008; 98 : 1619-1629.

13. Liu TG, Huang Y, Cui D, Huang $X-B$, Mao S-H, Ji L-L, Song $H B, Y i C$. Inhibitory effect of ginsenoside Rg3 combined with gemcitabine on angiogenesis and growth of lung cancer in mice statistical analysis. BMC Cancer 2009; 9: 250.

14. Zhang M, Tao W, Pan S, Sun X, Jiang $H$. Low-dose metronomic chemotherapy of paclitaxel synergizes with cetuximab to suppress human colon cancer xenografts. Anticancer Drugs 2009; 20: 355-363.

15. Zhang $Q$, Kang $X$, Zhao W. Antiangiogenic effect of lowdose cyclophosphamide combined with ginsenoside Rg3 on Lewis lung carcinoma. Biochem Biophys Res Commun 2006; 342: 824-828.

16. Ma $Y P$, Yang $Y$, Zhang $S$, Chen $X$, Zhang $N$, Wang $W$, Cao $Z X$, Jiang $Y$, Zhao $X$, Wei $Y Q$, et al. Efficient inhibition of lung cancer in murine model by plasmidencoding VEGF short hairpin RNA in combination with low-dose DDP. J Exp Clin Cancer Res 2010; 29: 56.

17. Machado DE, Berardo PT, Palmero CY, Nasciutti LE. Higher expression of vascular endothelial growth factor (VEGF) and its receptor VEGFR-2 (Flk-1) and metalloproteinase-9 (MMP-9) in a rat model of peritoneal endometriosis is similar to cancer diseases. $J$ Exp Clin Cancer Res 2010; 29: 4.

18. Kerbel RS, Kamen BA. The anti-angiogenic basis of metronomic chemotherapy. Nat Rev Cancer 2004; 4: 423-436.

19. Kerbel RS. Inhibition of tumor angiogenesis as a strategy to circumvent acquired resistance to anticancer therapeutic agents. Bioessays 1991; 13: 31-36.

20. Castilla MA, Caramelo C, Gazapo RM, Martín O, González-Pacheco FR, Tejedor A, Bragado R, AlvarezArroyo MV. Role of vascular endothelial growth factor (VEGF) in endothelial cell protection against cytotoxic agents. Life Sci 2000; 67: 1003-1013.

21. Magnon C, Galaup A, Rouffiac V, Opolon P, Connault E, Rose M, Perricaudet M, Roche A, Germain S, Griscelli $F$, et al. Dynamic assessment of antiangiogenic therapy by monitoring both tumoral vascularization and tissue degeneration. Gene Ther 2007; 14: 108-117.

22. Raspollini MR, Castiglione F, Garbini F, Villanucci AG, Baroni G, Boddi V, Taddei GL. Correlation of epidermal growth factor receptor expression with tumor microdensity vessels and with vascular endothelial growth factor expression in ovarian carcinoma. Int $J$ Surg Pathol 2005; 13: 135-142. 